\title{
Saturation level of the superficial zone of concrete and adhesion of repair systems
}

\author{
Luc Courard $^{\mathrm{a}, *}$, Jean-François Lenaers ${ }^{\mathrm{a}}$, Frédéric Michel ${ }^{\mathrm{a}}$, Andrzej Garbacz ${ }^{\mathrm{b}}$ \\ ${ }^{a}$ University of Liège, ArGEnCo Department, GeMMe Building Materials, Belgium \\ ${ }^{\mathrm{b}}$ Warsaw University of Technology, Institute of Technology and Organization of Building Technology, Poland
}

\section{A R T I C L E I N F O}

\section{Article history:}

Received 27 July 2010

Received in revised form 8 October 2010

Accepted 13 November 2010

Available online $\mathrm{xxxx}$

\section{Keywords:}

Concrete

Repair materials

Water

Saturation

Adhesion

\begin{abstract}
A B S T R A C T
Appropriate surface saturation level is essential for the durability of the repaired structure. The repair material is often blamed for "not sticking", although the general source of the trouble lies with the substrate surface conditioning. An extensive research project has been undertaken to develop specifications and performance criteria for surface preparation of concrete substrates. A field test was developed to evaluate the optimum moisture conditioning of the substrate concrete prior to application of repair material; this has been calibrated and compared with destructive and non-destructive on three types of concrete and two types of surface preparation. In order to evaluate different saturation levels, concrete samples have been stored in more than 12 modes of conservation. Finally, repair mortars have been applied on concrete substrates and adhesion was measured for different concrete surface saturation levels. Initial Surface Absorption Test (ISAT) can be used as an attractive quantitative test to evaluate saturation level of concrete substrate. Moreover, it is clearly shown that saturation levels higher than $50 \%$ and lower than $90 \%$ are requested for promoting adhesion of PCC mortars.
\end{abstract}

(c) 2010 Elsevier Ltd. All rights reserved.

\section{Introduction}

Water is the first cause of alteration of the adhesion between concrete and repair mortars: it may be present at the interface, or penetrate to it, and act through mechanical processes (freezing), chemical reactions (hydrolysis) or physical action (modification of interfacial forces) during and after repair operations. Faults and collapse of these may come from a misunderstanding of the real effect of water.

A lot of parameters affect the behavior of the interfacial zone $[1,2]$. In the case of repair operations, diffusion and permeability coefficients or water vapor transmission factor can explain these degradation mechanisms. The interface is submitted affected by several forms of water aggression (Fig. 1):

- firstly, water or aqueous solutions transfers may appear [3], due to migration and infiltration along the interface [4] or diffusion and capillary absorption from the zones to be repaired [5]. The resistance to these water movements will directly depend on the materials quality: $\mathrm{W} / \mathrm{C}$, porosity, etc.;

- secondly, water may be present before the application of the repair system. Partial or total saturation of concrete substrate is a common situation in repair works. Water along the inter-

* Corresponding author. Address: University of Liège, ArGEnCo Department, Research Group GeMMe, Building Materials, Chemin des Chevreuils, 1, B-4000 Liege, Belgium. Tel.: +32 436693 50; fax: +32 43669520 .

E-mail address: Luc.Courard@ulg.ac.be (L. Courard). face may avoid adhesion of the repair system, with regards to PC, PCC or CC type [1];

- thirdly, stresses and strains may be observed when reinforcement. Due to corrosion, steel reinforcement expands, inducing ruptures in the concrete substrate, in the repairing mortar or at the interface. Corrosion will depend again on water or other solutions at the interface, near to the reinforcement, but also on steel protection, alkalinity of the repairing mortar and its impermeability.

Water is always necessary and act as initiator or vector for degradation. When all the external causes of degradation are solved and deteriorated concrete has been removed [6], saturation level at the interface appears to be a predominant factor to promote adhesion of the repair system.

Saturated Surface Dry (SSD) conditioning of the substrate prior to application of cementitious repair materials is usually recommended and used, which underlies the "layman's" instinctive procedures to avoid problems, rather than achieving the most effective bond. Various investigators came to the conclusion that different substrates and repair materials correspond to different optimum interface moisture conditions at the time of casting. The problem is that there is presently no easy test method to determine the optimum moisture condition for a given combination of substrate and repair material.

The objective of the present work is to develop a technique to evaluate saturation level along the interface of the concrete substrate and to determine the optimum value of water level in order 


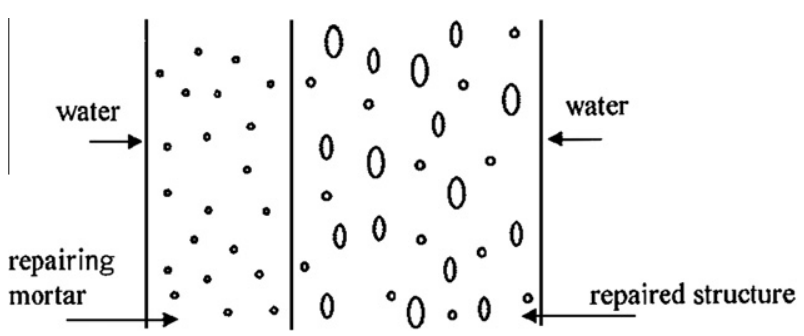

Fig. 1. Water intrusion into concrete, repair system and interface.

to promote adhesion of repair systems. Two main techniques are compared and evaluated, from the point of view of accuracy and easiness. Specific conditioning atmospheres are reproduced in order to obtain eight different saturation levels of concrete slabs. Finally, adhesion of a repair system is evaluated.

\section{Theoretical considerations}

When water comes between the repair (or coating) system and the concrete substrate, thermodynamic equilibrium is modified [7], with respect to particular values of surface free energies of materials $[8,9]$. From a theoretical point of view, this means a generalisation of the law of Young and Dupré [10], relatively to a new interface liquid-liquid. Contact angle modification is a visible effect of the interaction between the two liquids to conquer solid surface [11]. But what happens with spreading conditions? When equilibrium is attempted and if there is no spreading of one liquid to the detriment of the second one, equilibrium of forces means (Fig. 2):

$\gamma_{\mathrm{SA}}=\gamma_{\mathrm{SB}}+\gamma_{\mathrm{AB}} \cdot \cos \theta$

or

$\gamma_{\mathrm{SA}}-\gamma_{\mathrm{SB}}=\gamma_{\mathrm{AB}} \cdot \cos \theta$

where $\gamma_{\mathrm{SA}}, \gamma_{\mathrm{SB}}, \gamma_{\mathrm{AB}}$ and $\theta$ are interfacial tensions between solid $\mathrm{S}$ and liquids $\mathrm{A}$ and $\mathrm{B}$, interfacial tension between liquids $\mathrm{A}$ and $\mathrm{B}$, and contact angle of these liquids on the solid surface, respectively (Fig. 2).

It is possible to show [3] that the liquid with the higher tension of adhesion $\left(\gamma_{x} \cdot \cos \theta_{x}\right)$ will expulse the other one from the surface. The calculation of the work of adhesion allows interesting interpretations, taking into account the variation of surface free energies in presence of water [12]. The work of adhesion (3) is an "evaluation" of adhesion between the liquids and solids into contact with each other,

$W_{x(L)}=\gamma_{x(L)} \cdot\left(1+\cos \theta_{x(L)}\right)$

Observation of Table 1 clearly indicates the loss of adhesion when water is present at the interfaces between acrylic or epoxy resins and concrete.

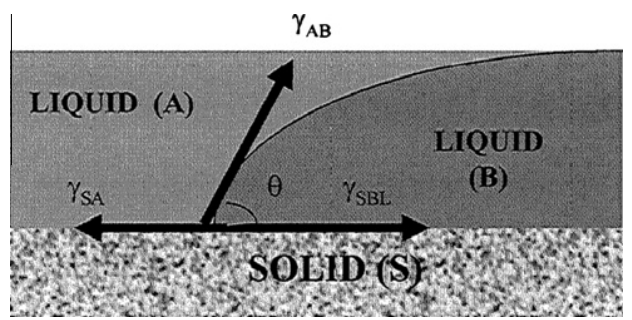

Fig. 2. Wetting of a solid surface by two immiscible liquids (the wetting is here favourable to liquid B).
Table 1

Calculation of work of adhesion for interfaces without $\left(W_{\mathrm{A}}\right)$ and with $\left(W_{\mathrm{AL}}\right)$ water [13].

\begin{tabular}{lll}
\hline Interface & $W_{\mathrm{A}}\left(\mathrm{mJ} / \mathrm{m}^{2}\right)$ & $W_{\mathrm{AL}}\left(\mathrm{mJ} / \mathrm{m}^{2}\right)$ \\
\hline Mortar/concrete & 87.8 & - \\
Acrylic/concrete & 74.1 & 22.7 \\
Acrylic/acrylic & 80.4 & 53.7 \\
Acrylic/hydrophobic treatment & 52.2 & 66.7 \\
Epoxy/concrete & 79.6 & 21.8 \\
Epoxy/epoxy & 92.4 & 53.0 \\
Epoxy/hydrophobic treatment & 56.0 & 42.2 \\
\hline
\end{tabular}

Work of adhesion does not mean automatically a good "technological" adhesion of the repair system on concrete substrate [14]. But it is a signal that conditions for good bonding are fulfilled or not: the lower the work of adhesion, the less is the chance to obtain strong physico-chemical interactions between solid and liquid phases. This is a necessary but not sufficient condition or adhesion [15].

\section{Experimental program}

\subsection{Research objectives}

The research program is performed in order to answer to the two main questions:

- how to objectively and rapidly evaluate concrete surface saturation level;

- how much this saturation level may affect adhesion?

In this aim, two main test methods have been performed: an "Initial Surface Absorption Test (ISAT)", developed on the base of Queen's University of Belfast testing device (Report 1987) [16] and a modified capillary suction (MCST) test, recently developed at the University of Liège [17]. The first proposed device offers several improvements with regards to other existing devices and makes it an attractive alternative for non-destructive field testing: it is compact, costs less, and the test duration is short (approximately $10 \mathrm{~min}$ ). Classical methods have also been used as references.

Finally, evaluation of the influence of saturation level on adhesion has been measured by means of pull-off test for two types of PCC mortars.

\subsection{Initial Surface Absorption Test (ISAT)}

Autoclam (Fig. 3 ) is a testing system for air and water permeability measurement of concrete (CNS Electonics) [19]. It can be used in the lab as well as on site: a metallic ring is fixed on the concrete substrate (Fig. 4) and the quantity of the fluid - air or water - that is pushed into the concrete for a classical pressure of $0.5 \mathrm{~kg}$ / $\mathrm{cm}^{2}$, is continuously registered. The rate of the linear curve between 5 and 15 min classically determines a permeability index.

\subsection{Modified capillary suction test (MCST)}

The most commonly used test to analyze water transfer at the interface is the capillary suction test [17]. It is described by several standards which essentially differ from the water level above the bottom surface of concrete specimen and the time when measurement is registered. Mass change is usually measured after 5 ,

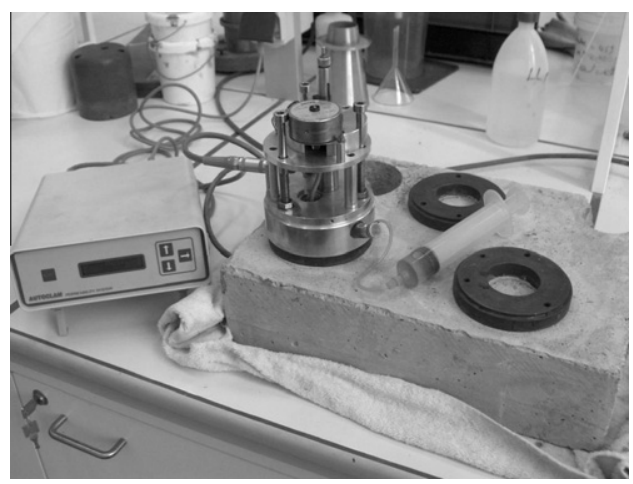

Fig. 3. Autoclam system and electronic controller. 


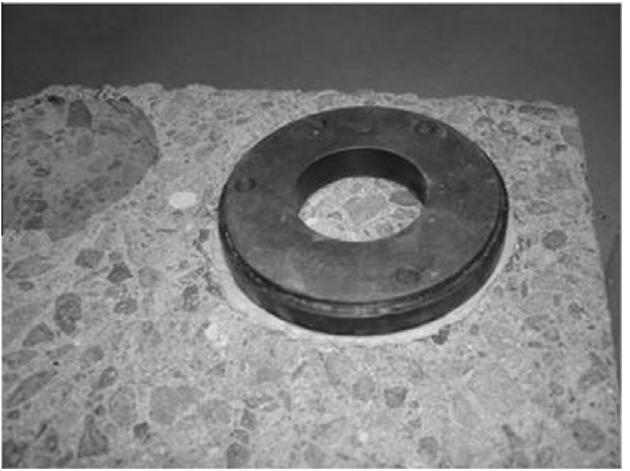

Fig. 4. Gluing the ring onto the concrete substrate (ISAT).

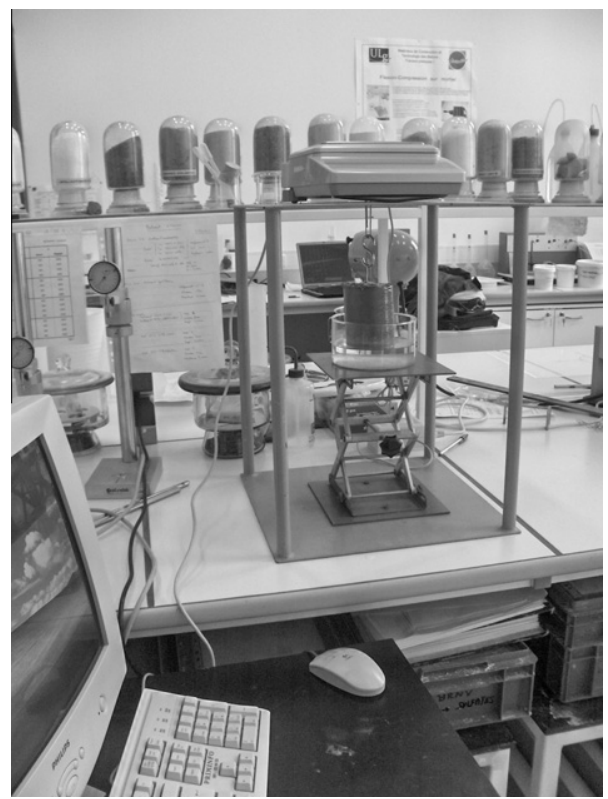

Fig. 5. Capillary suction test.

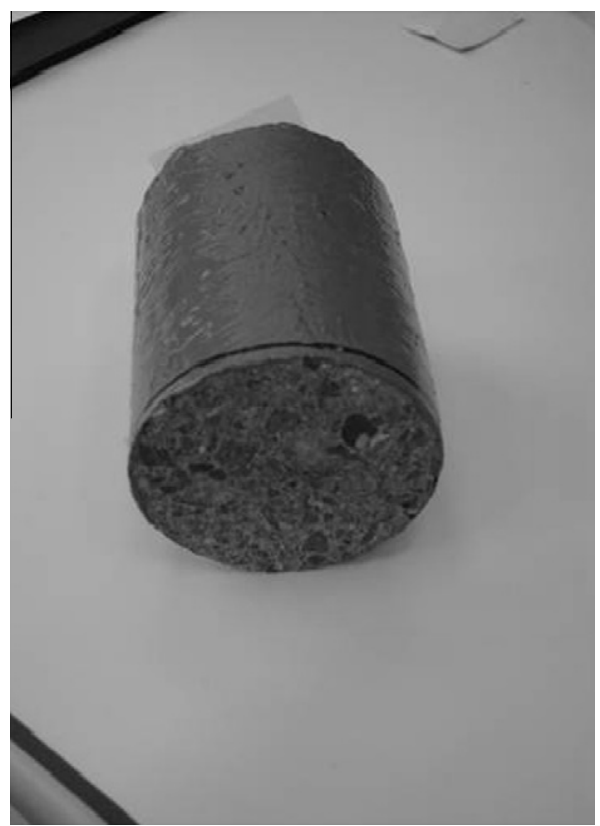

Fig. 6. Preparation of concrete cylinders for MCST test.
Table 2

Composition of concrete.

\begin{tabular}{llll}
\hline & $\begin{array}{l}\mathrm{C} 30 / 37 \\
\left(\mathrm{~kg} / \mathrm{m}^{3}\right)\end{array}$ & $\begin{array}{l}\mathrm{C} 40 / 50 \\
\left(\mathrm{~kg} / \mathrm{m}^{3}\right)\end{array}$ & $\begin{array}{l}\mathrm{C} 50 / 60 \\
\left(\mathrm{~kg} / \mathrm{m}^{3}\right)\end{array}$ \\
\hline CEM I 52.5 N & 275 & 325 & 375 \\
Sand 0/2 & 765 & 729 & 676 \\
Crushed aggregate 2/8 & 255 & 230 & 206 \\
Crushed aggregate 8/14 & 569 & 576 & 601 \\
Crushed aggregate 14/20 & 390 & 401 & 412 \\
Water & 192 & 186 & 182 \\
W/C & 0.70 & 0.57 & 0.49 \\
Mean compressive strength (MPa) & 42.9 & 54.3 & 61.2 \\
\hline
\end{tabular}



Fig. 7. Storage conditions referred 4, 5, 6, 7 and 8 .

15, 30 and $45 \mathrm{~min}$, as well as after 2, 6 and $24 \mathrm{~h}$ [20]. Mass is measured on samples wiped off with a damp tissue. However, capillary forces exist when contact is created between the concrete substrate and the repair system. The liquid phase wets the solid surface and goes up into the capillaries. A new test (MCST) is developed [17] to continuously measure mass change of the specimen during capillary action (Fig. 5).

Specimens are cylinders ( $\varnothing 80 \mathrm{~mm}$ ) with vertical faces coated with epoxy resin (Fig. 6) to avoid lateral penetration and/or evaporation of water: water comes up from the bottom until contact happens with the sample. Mass change is continuously monitored ( 1 or $5 \mathrm{~s}$ ) and the measurements obtained from a balance are saved through the application of appropriate computer software.

\section{Specimen preparation and conditioning}

\subsection{Concrete design and sample preparation}

Experiments are performed on three types of concrete: $\mathrm{C} 30 / 37$, C40/50, C50/60, respectively. The concrete mixtures are based on limestone crushed aggregates and Ordinary Portland Cement (Table 2).

Eighteen concrete slabs of $800 \times 600 \times 100 \mathrm{~mm}$ are cast. After casting $(24 \mathrm{~h})$, slabs are demoulded and stored into water up to 28 days. The compressive strength of concrete is measured for each mix on three cubes $150 \times 150 \times 150 \mathrm{~mm}$ (Table 2 ).

\subsection{Surface preparation}

After 28 days curing, the concrete slabs surfaces are prepared by sandblasting (SB) and hydro-jetting at 1000 bars pressure (HD); slabs with not any preparation (NT) are considered as references. The roughness of surface is checked by Sand Patch Test (EN 13036-1:2002) for sandblasting: an average texture depth equal to $0.60 \mathrm{~mm}$ is obtained. Cracks in the superficial zone of concrete are checked; only concrete prepared by hydro-jetting presents very small cracks [18].

\subsection{Storage conditions}

Concrete slabs are then stored in eight different climatic conditions, in such a way that it is possible to obtain saturation levels 


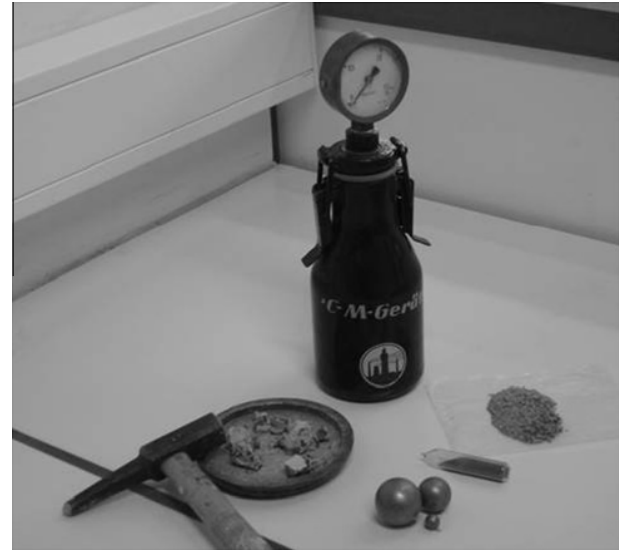

Fig. 8. Carbide bomb test.

from $40 \%$ to $100 \%$ (Table 3 ). The duration of storage is 3 months (Fig. 7).

The saturation level is determined by measuring water content of small drilled samples stored in the same conditions than larger slabs (Fig. 8).

Carbide bomb test (Fig. 8) has also been used for comparison with weighing method (Fig. 9).

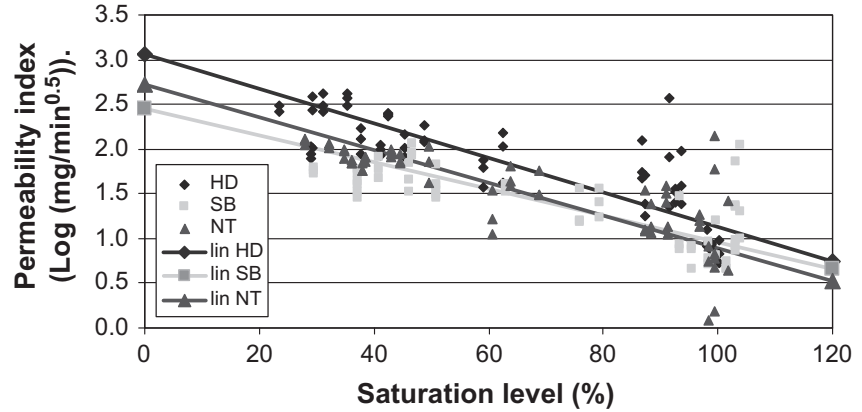

Fig. 11. Permeability index versus degree of saturation (ISAT).

\section{Analysis of the results}

\subsection{Results of water absorption tests}

Water absorption permeability indexes (Fig. 10) give relatively high correlations with degree of saturation (Fig. 11). Statistically speaking however, there is no influence of the quality of concrete, with regard to its compressive strength. On the contrary, for a specific resistance, a light influence of the surface preparation seems to be possibly pointed out: absorption rate is higher for surfaces

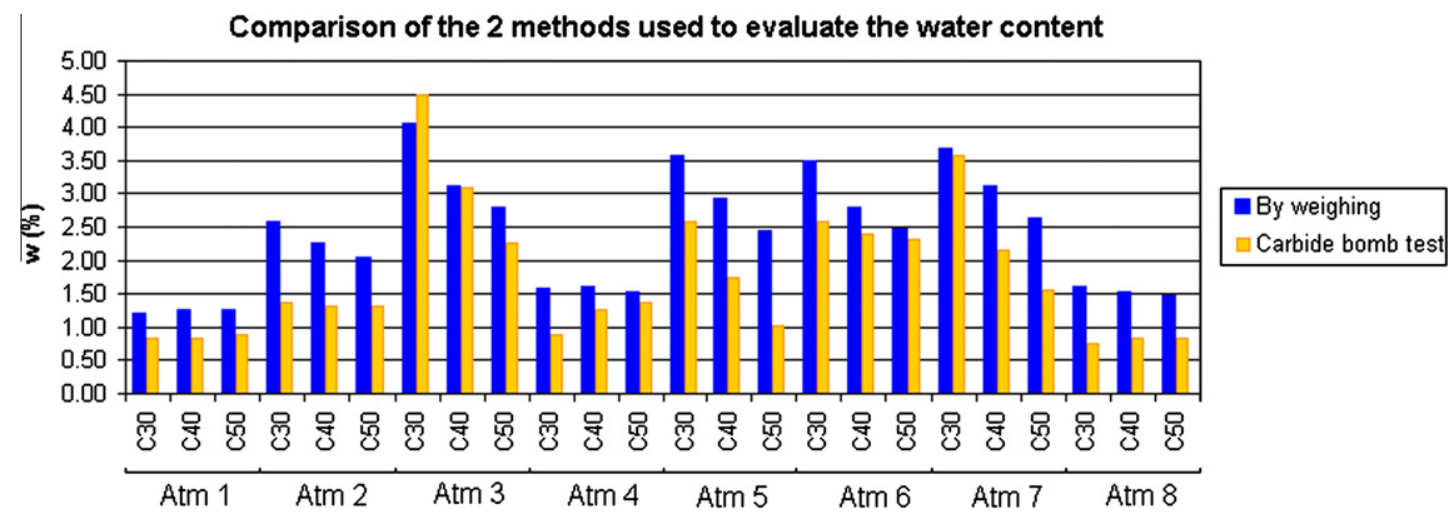

Fig. 9. Comparison of water content of concrete samples, obtained with weight method and carbide bomb method.

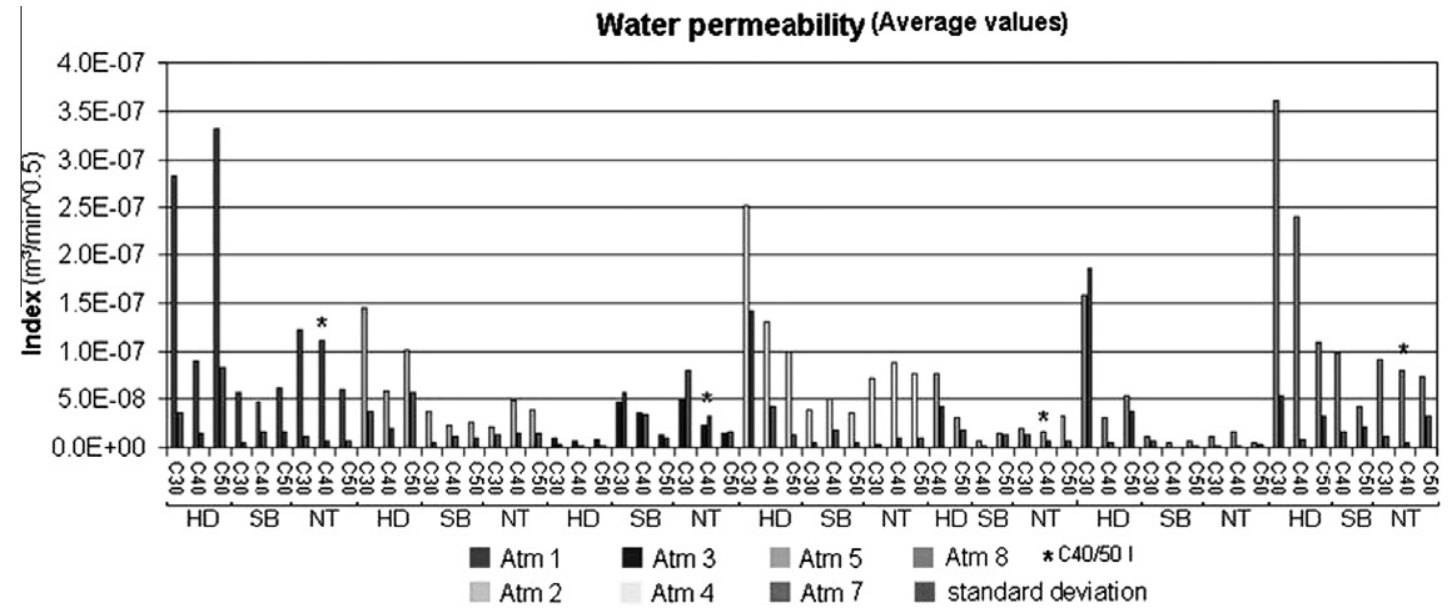

Fig. 10. Permeability index for the different conditions: concretes, storage conditions (Atm) and surface preparation. 


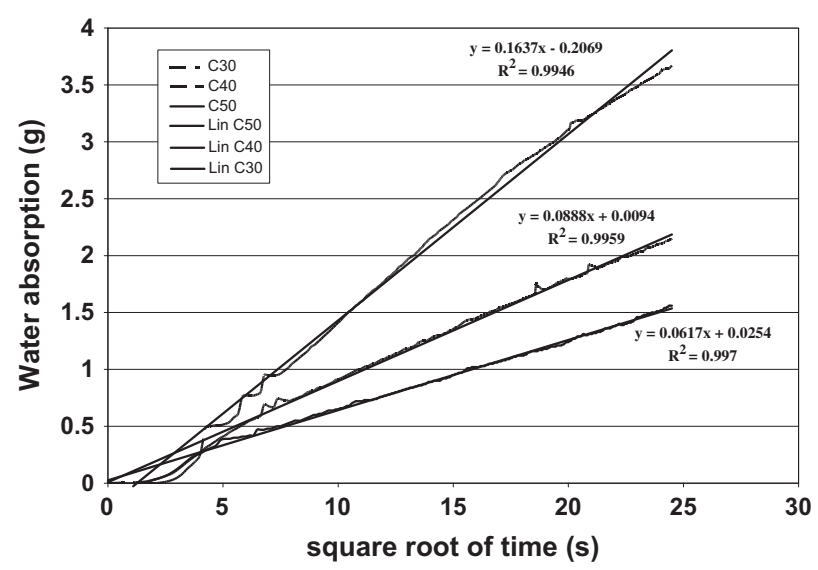

Fig. 12. Capillary absorption coefficients for atmosphere four and hydro-jetting.

prepared by hydro-jetting (HD) than sandblasting (SB), maybe due to the presence of cracking in the superficial zone of concrete.

Good correlation between permeability index and the degree of saturation is also observed: the higher the saturation, the higher the permeability index (Fig. 11). The dispersion of the results remains however important, especially for saturation level higher than $80 \%$.

Water capillary absorption tests (MCST) give clearer and less dispersive information (Fig. 12): the strongest the concrete, the lower the absorption coefficient. The parameters influencing the test procedure are of course more easily controllable.

Once again, no effect of concrete strength can be detected. The degree of saturation has however a clear effect on capillary absorption (Fig. 13). For surface preparation effect, the same conclusions than before can be given: the hydro-jetting induces a higher rate of water capillary absorption, which probably can be correlated to soft microcracking.

\subsection{Comparison of the two methods}

Same tendencies are observed for the two methods (Fig. 14).

The coefficients of correlation with the degree of saturation are however systematically higher with MCST than with ISAT (Table 4).

The higher variation and dispersion of results for ISAT may come from the difficulties of performing the test and, specifically, the waterproofing of the connection between the metallic ring and the substrate (Fig. 7). Moreover, dispersion may generally be induced by the:

- variation of the concrete: the microstructure of the concrete, especially along the surface, may vary from one to another location;

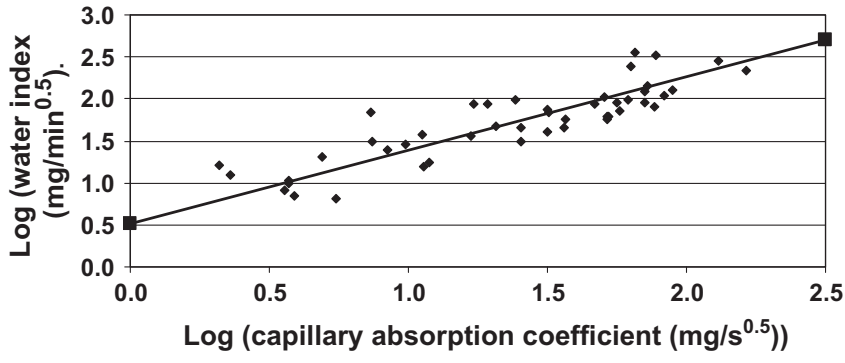

Fig. 14. Comparison between permeability index and capillary absorption.

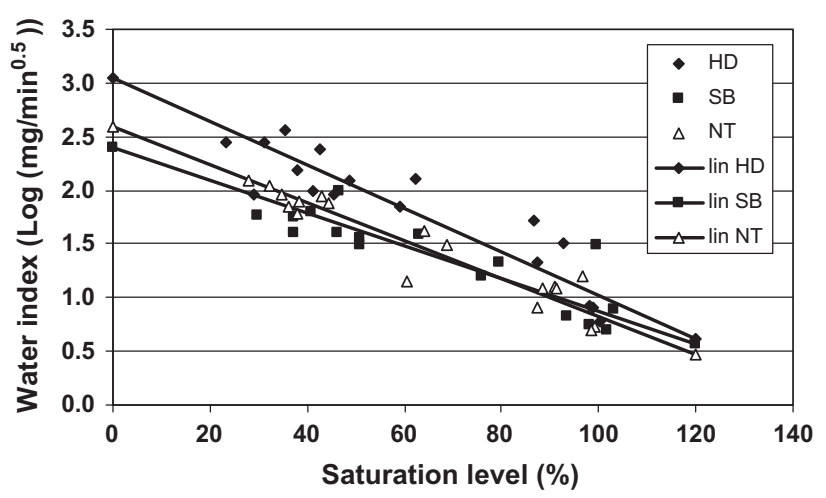

Fig. 15. Permeability index versus degree of saturation (ISAT) after elimination of extreme values.

- approximation of the evaluation of the degree of saturation. If these are measured on samples stored in the same conditions than concrete slabs, real saturation level of the concrete is probably not really and precisely known;

- test conditions: tests are realized in laboratory conditions (50\% R.H. and $\left.23^{\circ} \mathrm{C}\right)$. That means that the samples are taken out of their storage conditions during testing time. Water vapor exchanges may happen during the test.

If "extra" values are eliminated, corresponding to specific behaviors "out of the range", quite good correlations are assumed, with correlation coefficients of $0.82,0.73$ and 0.90 for HD, SB and NT, respectively (Fig. 15).

\section{Adhesion and saturation level}

Evaluation of the influence of saturation level on adhesion has been measured by means of pull-off test for two types of PCC

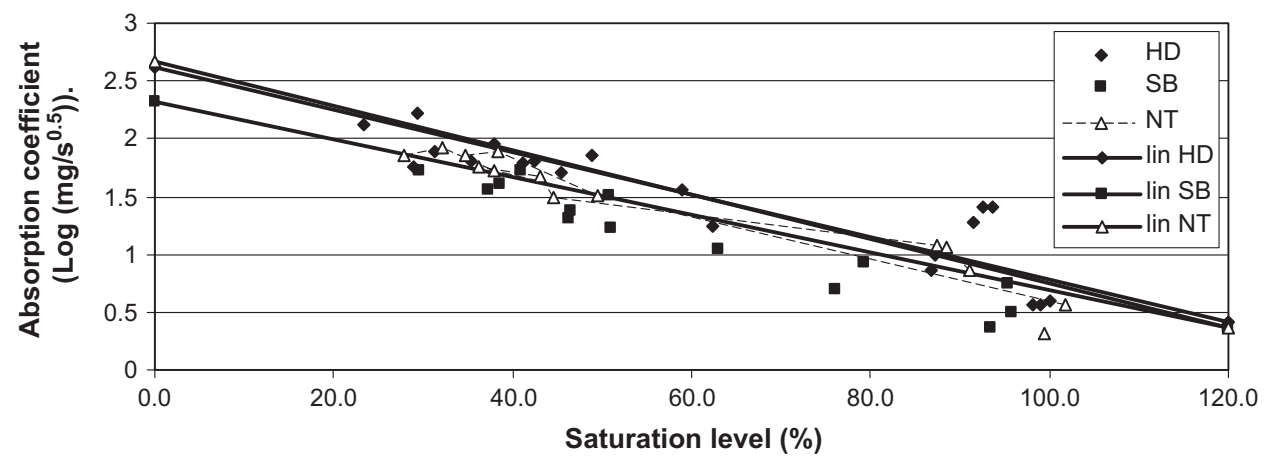

Fig. 13. Capillary absorption rate versus degree of saturation (MCST). 
Table 3

Storage conditions and saturation levels.

\begin{tabular}{clc}
\hline Atm & Storage conditions (SC) & $\begin{array}{c}\text { Saturation } \\
\text { level (\%) }\end{array}$ \\
\hline 1 & $\begin{array}{l}\text { Dried }\left(40{ }^{\circ} \mathrm{C} \text { in air oven until constant weight) and stored }\right. \\
\text { at } 85 \% \text { relative humidity } / 23^{\circ} \mathrm{C}\end{array}$ & 32 \\
2 & $\begin{array}{l}\text { Stored outside (wintery temperature and protection from } \\
\text { rain) }\end{array}$ & 64 \\
3 & $\begin{array}{l}\text { Stored at } 100 \% \mathrm{RH} / 20{ }^{\circ} \mathrm{C} \text { (humid climatic room) } \\
\text { Dried, immerged into water for } 30 \mathrm{~s} \text { and stored in a } \\
\text { plastic bag }\end{array}$ & 100 \\
5 & $\begin{array}{l}\text { Stored in water, taken out for } 3 \mathrm{~h}\left(50 \% \mathrm{RH} / 23{ }^{\circ} \mathrm{C}\right) \text { and } \\
\text { stored in a plastic bag }\end{array}$ & 90 \\
6 & $\begin{array}{l}\text { Idem } 5 \text { but kept } 1 \mathrm{~h} \text { out of water before packing in plastic } \\
\text { bag }\end{array}$ & 92 \\
7 & $\begin{array}{l}\text { Idem } 5 \text { but kept } 15 \text { min out of water before packing in } \\
\text { plastic bag }\end{array}$ & 96 \\
8 & Stored at $50 \% \mathrm{RH} / 23{ }^{\circ} \mathrm{C}$ (laboratory conditions) & 42 \\
\hline
\end{tabular}

mortars referred $A$ and $B$, respectively, with the following characteristics:

- mortar A is a two-component mortar with a ratio liquid component/powder component $=105 / 1000$ in weight. A bonding layer - acrylic slurry - is necessary before application of the mortar. The mortar is of acrylic type with a characteristic bending strength of $11 \mathrm{MPa}$, a characteristic compressive strength of $54.98 \mathrm{MPa}$ and a density equal to 1.87 ;

- mortar B is a one-component mortar with a ratio water/powder component 95/1000. Slurry is also needed. The mortar is of acrylic type with a characteristic bending strength of 10.94 MPa, a characteristic compressive strength of $48.36 \mathrm{MPa}$ and a density equal to 2.18 ;

The repair systems are applied on the sandblasted concrete slabs. The cohesion of concrete is equal to $4.16 \mathrm{~N} / \mathrm{mm}^{2}$. Concrete slabs are stored as mentioned here above (Table 3 ) in order to reproduce different saturation levels.

The slabs are vertically positioned and the mortar is applied with a thickness of $10 \mathrm{~mm}$. The slabs are taken out of the bags only when the components are mixed or the slurry is ready to be used. Wet and dry slurries are applied on each half part of the slab. The time between the application of the slurry and the application of mortar is about $30 \mathrm{~s}$, according to producer recommendations. The samples are then stored for 28 days at $20{ }^{\circ} \mathrm{C} / 65 \%$ R.H. Three core-samples of $50 \mathrm{~mm}$ diameter are taken out of each half slab and adhesion is measured according to EN 1542. All ruptures modes are in the near-to-surface of concrete (quasi adhesive ruptures).

Adhesion strength changes as a function of the water saturation level of the substrate (Tables 5 and 6 ). The adhesion is relatively weak for low saturation levels $(\leqslant 50 \%)$; it reaches classical values for saturation levels between $55 \%$ and $75 \%$. Above these ranges, a decrease of strength $(>90 \%)$ is observed.

A weak saturation level produces a disturbance into the setting process of the cement, while a too high saturation level acts on the
Table 5

Adhesion of mortar A on concrete substrate versus saturation level of concrete substrate and slurry.

\begin{tabular}{lll}
\hline Adhesion $\left(\mathrm{N} / \mathrm{mm}^{2}\right)$ & & \\
\hline Saturation level & With dry slurry & With wet slurry \\
\hline 50 & 0.83 & 2.32 \\
52 & 2.80 & 2.14 \\
55 & 2.09 & 2.89 \\
70 & 2.75 & 2.65 \\
90 & 3.54 & 3.36 \\
93 & 2.13 & 3.06 \\
97 & 1.81 & 2.58 \\
100 & 1.43 & 1.48 \\
\hline
\end{tabular}

Table 6

Adhesion of mortar B on concrete substrate versus saturation level of concrete substrate and slurry.

\begin{tabular}{lll}
\hline Adhesion $\left(\mathrm{N} / \mathrm{mm}^{2}\right)$ & & \\
\hline Saturation level & With dry slurry & With wet slurry \\
\hline 50 & 1.41 & 1.34 \\
60 & 2.90 & 2.72 \\
70 & 2.95 & 1.41 \\
100 & 1.09 & 1.43
\end{tabular}

attraction forces, the porosity, the kinetics of contact and, finally, the adhesion properties. Optimal moisture of the substrate will be obtained by conservation at $100 \%$ relative humidity, which can be easily reached in a laboratory. Consequently, best adhesion values are reached for a large scale of saturation levels; that means that it does not extensively depend on slight variations of water content, except for extreme conditions.

The influence of water content of the slurry seams to be negligible for mortar A between $70 \%$ and $90 \%$ of substrate saturation level (Table 5). Out of this range, the wet slurry always gives better results. For mortar $\mathrm{B}$, the adhesion values with dry slurry seems to be better than with wet slurry (Table 6); this can be due to the fact that, since mortar B uses only water - and not polymeric emulsion - there is an increase of $\mathrm{W} / \mathrm{C}$ and then an increase of porosity. The quantification of the range of the saturation level of the concrete substrate is consequently of the prime importance for the adhesion characteristics and is directly useful for the contractors.

Saturation level of the concrete substrate surface at the time of application of repair material has a major influence on the absorption of moisture and fine particles from the fresh (plastic) repair material, and therefore on bond strength and durability.

It must be mentioned that pure organic coatings present a totally different behavior when affected by water at the interface [9].

\section{Conclusions}

The following conclusions may be reached from the present investigations concerning the measurement of water saturation le-

Table 4

Correlation coefficients for ISAT and MCST methods versus saturation level.

\begin{tabular}{|c|c|c|c|c|c|c|}
\hline \multirow[t]{2}{*}{ Surface preparation } & \multicolumn{3}{|l|}{ ISAT } & \multicolumn{3}{|l|}{ MCST } \\
\hline & & $r$ & $r^{2}$ & & $r$ & $r^{2}$ \\
\hline HD & sat/log (index) & -0.80 & 0.64 & sat/log (abs) & -0.90 & 0.80 \\
\hline SB & sat/log (index) & -0.73 & 0.53 & sat/log (abs) & -0.96 & 0.91 \\
\hline NT & sat/log (index) & -0.78 & 0.62 & sat $/ \log (\mathrm{abs})$ & -0.96 & 0.93 \\
\hline
\end{tabular}

Index = permeability index.

Abs $=$ absorption rate. 
vel and its effect on adhesion of cementitous and PCC repair systems:

- ISAT can be used as an attractive quantitative test to evaluate saturation level of concrete substrate; it is compact, costs less and quick;

- ISAT results (permeability index) are not sensitive to concrete compressive strength, in the range from 30 to $50 \mathrm{MPa}$; they are influenced by the surface quality but it is difficult to conclude if it is actually due to the cracking or to the roughness;

- however, the higher variation and dispersion of results for ISAT may come from the difficulty of performing the test with rough concrete surface (after hydro-jetting);

- MCST test gives clearer and less dispersive information than ISAT, with higher correlation with water content measurement (wet and dry weighing);

- there is a very good correlation between water absorption index and capillary absorption coefficient determined with ISAT and MCST tests, respectively;

- there is a large range of saturation levels (50-90\%) where adhesion remains high and constant, which seems to limit the influence of environmental conditions on adhesion of hydraulic binder based repair systems; the adhesion is relatively weak for low saturation levels (50\%); it reaches classical values for saturation levels between $55 \%$ and $90 \%$;

- when acrylic emulsion is used as bonding layer, highest saturation levels induce water film at the interface, which is incompatible with polymeric material and artificially reduce the work of adhesion.

This clearly points out the effect of water in the concrete superficial zone and the difficulty to accurately evaluate the saturation level. Saturation levels from 55\% to $90 \%$ must be attempted for CC and PCC repair systems; ISAT may give a good indication of water content on relatively smooth surface.

\section{Acknowledgements}

The research project "Development of Self Compacting Mortars for Maintenance and Repair of Concrete Infrastructures" is financially supported by the Government of Poland (KBN) and Wallonia Brussels International Agency, Belgium.

\section{References}

[1] Courard L, Degeimbre R, Darimont A, Wiertz J. Influence of composition of repairing mortars on adhesion. In: van Gemert D, editor. Proceedings of the VIII international congress on polymers in concrete (KULeuven en KVIV), Oostende, 1995. p. $119-24$.
[2] Pareek SN. Improvement in adhesion of polymeric repair and finish materials for reinforced concrete structures. Doctorate Dissertation, Nihon University, College of Engineering (Japan); 1993. 182p.

[3] Courard L, Degeimbre R, Darimont A, Wiertz J. Hygro-thermal application conditions and adhesion. In: Seidler $P$, editor. Proceedings of the fifth international colloquium industrial floors '03 (Technische Akademie Esslingen), Ostfildern/Stuttgart; 2003. p 137-42.

[4] Courard L, Darimont A. Appetency and adhesion: analysis of the kinetics of contact between concrete and repairing mortars. In: Katz A, Bentur A, Alexander M, Arliguie G, editors. Proceedings of the RILEM international conference, interfacial transition zone in cementitious composites. Haïfa: E\&FN Spon; 1998. p 185-94.

[5] Courard L, Degeimbre R, Darimont A, Wiertz J. Effects of sunshine/rain cycles on the behaviour of repair systems. In: Ohama Y, Puterman M, editors. ISAP 99, proceedings of the 2nd international RILEM symposium on adhesion between polymers and concrete, Dresden, 1999. p. 511-21.

[6] Bissonnette B, Courard L, Vaysburd A, Bélair N. Concrete removal techniques: influence on residual cracking and bond strength. Concr Int 2006;28(12):49-55.

[7] Courard L. How to analyse thermodynamic properties of solids and liquids in relation with adhesion? In: Ohama Y, Puterman M, editors. ISAP 99, proceedings of the 2nd international RILEM symposium on adhesion between polymers and concrete, Dresden; 1999. p. 9-20.

[8] Courard L. Parametric study for the creation of the interface between concrete and repair products. Mater Struct 2000;33:65-72.

[9] Courard L, Degeimbre R, Wiertz J. The behaviour of coatings on concrete substrates in relation with different forms of water attack. In: Gjorv OE, Sakai $\mathrm{K}$, Banthia N, editors. CONSEC ' 98 , proceedings of the 2 nd international conference on concrete under severe conditions. Tromso: E\&FN Spon; 1998. p. 997-1006.

[10] Comyn J. Contact angles and adhesive bonding. Int J Adhes Adhes 1992;12(3):145-9.

[11] Courard L, Degeimbre R, Darimont A, Wiertz J. Effects of environment on repair materials: results of a five-year research project. In: Malhotra VM, editor. Proceedings of the sixth canmet/ACI international conference on durability of concrete (SP212-57), Thessaloniki; 2003. p. 921-40.

[12] Courard L, Degeimbre R, Wiertz J, Van de Put M. Analysis of the resistance to water of the interface between concrete and repairing systems: experimental approach. In: Gjorv OE, Sakai K, Banthia N, editors. E \&FN SponCONSEC ‘ 98 , proceedings of the 2nd international conference on concrete under severe conditions, Tromso; 1998. p. 988-96.

[13] Courard L. Evaluation of thermodynamic properties of concrete substrates and cement slurries modified with admixtures. Mater Struct 2002;35:149-55.

[14] Gutowski W. The relationship between the strength of an adhesive bond and the thermodynamic properties of its component. Int $\mathrm{J}$ Adhes Adhes 1987;7(4):189-98.

[15] Posart W, Kamuzewitz H. The thermodynamics and wetting of real surfaces and their relationship to adhesion. Int J Adhes Adhes 1993;13(2):77-84.

[16] Permeability testing on site concrete. A review of methods and experience. Concrete society technical report, 31. London: Concrete Society Working Party; 1987.

[17] Courard L, Degeimbre R. A capillary suction test for a better knowledge of adhesion process in repair technology. Can J Civil Eng 2003;30(6):1101-10.

[18] Courard L, Lenaers JF. Evaluation of saturation and microcracking of the superficial zone of concrete: new developments. In: Alexander et al., editor. Proceedings of the ICCRRR08 international congress on concrete repair, reinforcement and retrofitting 2009. London, Cape Town: Taylor \& Francis Group; 2008. p. 977-82.

[19] CNS Electronics Ltd., Autoclam.

[20] Justnes H. Capillary suction of water by polymer cement mortars. In: van Gemert D, KULeuven en KVIV, editors. Proceedings of the RILEM symposium on properties and test methods for concrete-polymer composites, Oostende; 1995. p. 29-37. 